\title{
Study Of P-AFS Algorithms Based On Navigation Signals And Digital Map
}

\author{
Du Xiaofang \\ School of Automotive Engineering, Hubei Key \\ Laboratory Advanced Technology for Automotive \\ Components \\ Wuhan University of Technology \\ Wuhan,China \\ E-mail : $\underline{1371214842 @ \text { qq.com }}$ \\ Ju Jiangshan \\ Hubei Collaborative Innovation Center for Automotive \\ Components Technology \\ Wuhan University of Technology \\ Wuhan,China \\ E-mail :jujujiangshan@163.com \\ Wang Haixing \\ School of Automotive Engineering, Hubei Key \\ Laboratory Advanced Technology for Automotive \\ Components \\ Wuhan University of Technology \\ Wuhan,China \\ E-mail :1103147210@qq.com
}

\author{
Liu Genhui \\ Huazhong University of Science and Technology \\ Wuhan, China \\ E-mail:genhuiliu@163.com
}

\author{
Cao Yan \\ Department of Equipment Command and \\ Administration \\ Academy of Armored Force Engineering, \\ Beijing,China \\ E-mail:cy1840@163.com
}

\begin{abstract}
Intelligent headlamps AFS (Adaptive frontlighting system) can significantly improve safety of nighttime driving behivior, bending mode algorithm of conventional AFS are basically based on vehicle speed and steering wheel angle signal/ road wheel steer angle signals to control the swiveling angle of headlamps, such algorithms sometimes hysteresis and imprecise. This paper presents a new P-AFS algorithm, the algorithm can effectively use navigation signals and digital map data , and control the swiveling angle of headlamps based on vehicle speed and road curvature. Set up mathematical model and control algorithm of actuator, established a confederative simulation model of carsim and simulink, tested and verified the algorithm, the P-AFS algorithm can effectively eliminate the hysteresis and improve accuracy of traditional AFS.
\end{abstract}

Keywords-P-AFS; algorithm; mathematical model; simulation

\section{INTRODUCTION}

In the process of vehicle driving, the required information of driver obtained by the faculty of sight accounting for $80-90 \%$ of the total [1]. When vehicle driving on the highway, intercity highways ,rural roads or other poor illumination road at night, lighting in front of the car main provided by the headlights. In poor lighting conditions, visual information available for the drivers is deficient. Statistics shows that: although traffic volume of nighttime is small, but probability of accidents happen at night more than three times during the day[2].A higher probability of night traffic accidents is closely related to poor road lighting conditions, thus improving performance of headlamps is extremely important. Currently, road traffic conditions are more and more complex and the automobile power performance is higher and higher, in this case ,the intelligent headlamps AFS(Adaptive front-lighting system) have appeared. AFS can significantly improve the illumination effects on various road conditions and increase safety of nighttime driving behavior.

Conventional AFS controls the swiveling angle of headlamps are basically based on vehicle speed and steering wheel angle signal/road wheel steer angle signals when the vehicle is traveling on a curve, the control algorithm is very effective when the vehicle is traveling on a circular curve, but such algorithms are either hysteresis and imprecise before vehicle enter the curve, when vehicle is located on the S-shaped curve or transition curve.

This paper presents a bending mode algorithm of PAFS (Predictive Adaptive front-lighting system) based on navigation signals and digital map. The algorithm is more accurate and can effectively eliminate hysteresis of conventional AFS system.

In the field of vehicle navigation, traffic vector map must be used, vector map organized by coordinates $(\mathrm{x}, \mathrm{y})$ under rectangular plane coordinate system, based on this 
feature, the data associated with this algorithm includes nodes and shape points.Nodes: road intersections, road shape change points, road attribute change points, end of the roads,other points which can define the relationship between the road and topological properties. Shape points:points except nodes, in order to describe geometric shapes of road more accurately.Because the nodes and road shape points of electronic map save as vectors, so these data can be used for navigation, of course, these data also can be applied to bending mode algorithm of PAFS.

If the vehicle get navigation signal, and navigation signal with the electronic map are matched then vehicle position in electronic map would have been obtained. Navigation signal acquisition and map-matching this paper will not involved, there are bending mode algorithm of P-AFS after the completion of map-matching.

\section{BENDING MODE ALGORITHM OF P-AFS}

Andrew. Liu and Dario. Salvucci [6] studied the driver's front view behavior, and defined actual range of observation of driver :the region that vehicle will travel in the next $2-5 \mathrm{~s}$ (calculate according to the current vehicle speed). Then the mathematical model formulated in this article should ensure the headlights illuminate the abovementioned region ahead of the vehicle.

Because of the complexity of vehicle dynamics, use steering wheel angle signal/ road wheel steer angle signals as input to control the swiveling angle of headlamps can not sufficiently accurate. This paper will use vehicle speed and road curvature as control parameters to get the swiveling angle of headlamps.Considering the complexity of the actual road shape, a concept is introduced: the equivalent radius $\overline{\mathrm{R}}$ and the equivalent curvature $\bar{\rho}$, where $\bar{\rho}=1 / \overline{\mathrm{R}}$.

The equivalent radius as shown in Fig. $1, \mathrm{O}$ is the current positon of vehicle, $\mathrm{A}$ is the positon of center gravity of vehicle after about $2.5 \mathrm{~s}, \mathrm{~B}$ is the positon of center gravity of vehicle after about $5 \mathrm{~s}$ (calculate according to the current vehicle speed). O, A, B as the three points on a circle, the center of the circle is $\mathrm{O}^{\prime}$, the radius of the circle is $\bar{R}$.

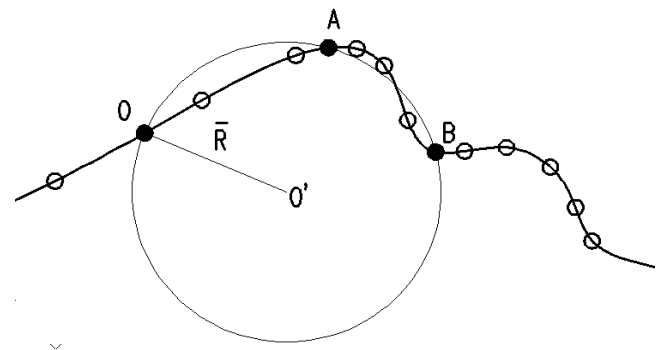

Figure1 schematic view of equivalent radius

Algorithm obtaining $\bar{R}$ as follows: if the coordinates of road nodes and shape points are known, and the longitude and latitude were converted to coordinates under rectangular plane coordinate system, these coordinates are sorted according to the direction of vehicle travel, then $a_{i}=\left(x_{i}, y_{i}\right), i=0,1,2 \ldots \ldots, x_{i}, y_{i}$ is the abscissa and ordinate of $\mathrm{i}$-th point respectively. If the current coordinate of vehicle under rectangular plane coordinate system is $\mathrm{a}=(\mathrm{x}, \mathrm{y})$, $\mathrm{a}$ is between $\mathrm{a}_{\mathrm{n}}$ and $a_{n+1}$, and $\vec{v} \cdot \overrightarrow{a_{n} a_{n+1}} \geq 0$. (1) $\left\|a_{n+1}-a\right\|_{2}=s_{1}, \| a_{n+1}-$ $\mathrm{a}_{2}+\left\|\mathrm{a}_{\mathrm{n}+2}-\mathrm{a}_{\mathrm{n}+1}\right\|_{2}=\mathrm{s}_{2} \quad, \quad\left\|\mathrm{a}_{\mathrm{n}+1}-\mathrm{a}\right\|_{2}+$ $\left\|a_{n+2}-a_{n+1}\right\|_{2}+\cdots+\left\|a_{n+j}-a_{n+j-1}\right\|_{2}=s_{j}$ $\mathrm{j}=1,2 \ldots$..(2)If $\mathrm{s}_{\mathrm{j}}<2.5 * \mathrm{~V} / 3.6$, then return to (1); if $\mathrm{s}_{\mathrm{j}}=2.5 * \mathrm{~V} / 3.6$, coordinate of $\mathrm{A}$ were obtained as $a_{n+j}=\left(x_{n+j}, y_{n+j}\right)$;if $s_{j}>2.5 * V / 3.6$, then $\Delta s_{1}=s_{j}-$ $2.5 * \mathrm{~V} / 3.6 \quad, \quad \Delta \mathrm{s}_{2}=2.5 * \mathrm{~V} / 3.6-\mathrm{s}_{\mathrm{j}-1} \quad$,if $\Delta \mathrm{s}_{1}>$ $\Delta \mathrm{s}_{2}$, coordinate of $\mathrm{A}$ were obtained as $\mathrm{a}_{\mathrm{n}+\mathrm{j}-1}=$ $\left(x_{n+j-1}, y_{n+j-1}\right)$,otherwise,coordinate of A were obtained as $a_{n+j}=\left(x_{n+j}, y_{n+j}\right)$.(3) After completion of the above, $\quad\left\|a_{n+1}-a\right\|_{2}=s_{1}, \quad\left\|a_{n+1}-a\right\|_{2}+$ $\left\|a_{n+2}-a_{n+1}\right\|_{2}=s_{2},\left\|a_{n+1}-a\right\|_{2}+\left\|a_{n+2}-a_{n+1}\right\|_{2}+$ $\cdots+\left\|a_{n+h}-a_{n+h-1}\right\|_{2}=s_{h} \quad, h=1,2, \ldots$ (4)If $\quad s_{h}<5 *$ $\mathrm{V} / 3.6$, then return to (3);if $\mathrm{s}_{\mathrm{h}}=5 * \mathrm{~V} / 3.6$, coordinate of $\mathrm{B}$ were obtained as $a_{n+h}=\left(x_{n+h}, y_{n+h}\right)$;if $s_{h}>5 *$ $\mathrm{V} / 3.6$, then $\Delta \mathrm{s}_{3}=\mathrm{s}_{\mathrm{h}}-5 * \mathrm{~V} / 3.6, \Delta \mathrm{s}_{4}=5 * \mathrm{~V} / 3.6-$ $\mathrm{s}_{\mathrm{h}-1}$, if $\Delta \mathrm{s}_{3}>\Delta \mathrm{s}_{4}$, coordinate of $\mathrm{B}$ were obtained as $\mathrm{a}_{\mathrm{n}+\mathrm{h}-1}=\left(\mathrm{x}_{\mathrm{n}+\mathrm{h}-1}, \mathrm{y}_{\mathrm{n}+\mathrm{h}-1}\right)$, otherwise coordinate of $\mathrm{B}$ were obtained as $a_{n+h}=\left(x_{n+h}, y_{n+h}\right)$.(5) Clearly, $h \geq j$. If $h=j$, the coordinates of $A, B$ point are equal, such cases may be the road curvature is very small, close to straight line, so the shape points is very sparse;may also be vehicle speed is very small; and if the $\mathrm{A}, \mathrm{B}$ point coordinates are equal as $\mathrm{a}_{\mathrm{m}}=\left(\mathrm{x}_{\mathrm{m}}, \mathrm{y}_{\mathrm{m}}\right), \mathrm{m} \in$ $\{i=0,1,2 \ldots\}$, at this time only two points, can not determine a circle, take the coordinates of $\mathrm{A}$ as $\mathrm{a}_{\mathrm{m}}=$ $\left(\mathrm{x}_{\mathrm{m}}, \mathrm{y}_{\mathrm{m}}\right)$, and take the coordinates of $\mathrm{B}$ as $\mathrm{a}_{\mathrm{m}+1}=$ $\left(\mathrm{x}_{\mathrm{m}+1}, \mathrm{y}_{\mathrm{m}+1}\right)$. (6) Determine future travel direction of automobile based on movement parameters and distribution of coordinates. The end of algorithms.

After acquiring the important parameters $\bar{R}$, swiveling angle of headlamps $\theta 1$ at different locations of road can be obtained based on the formula (1).

$$
\theta 1=\mathrm{S} / 2 \mathrm{R}=\frac{5 * \mathrm{~V} * 180}{3.6 * 2 * \overline{\mathrm{R}} * \pi}
$$

While use comparative algorithm to verify the superiority of proposed algorithm, $\theta 2$ is swiveling angle of headlamps obtained by comparative algorithm.

$$
\theta 2=\mathrm{S} / 2 \mathrm{R}=\frac{5 * \mathrm{~V} * 180}{3.6 * 2 * \mathrm{R} * \pi}
$$

Wherein: $\mathrm{R}^{\prime}=\frac{\mathrm{L}}{\sin \delta}, \delta$ :the front road wheel steer angle, $\mathrm{R}^{\mathrm{i}}$ :turning radius based on Ackermann steering principle.

\section{MATHEMATICAL MODEL OF ACTUATOR}

Stepper motor is the actuator which convert the input signal to angular displacement. In the P-AFS headlamps this paper relates to, in order to achieve the level swiveling of headlights, left and right headlights need a stepper motor respectively. A sort of of two-phase hybrid stepper motor has be selected,which basic parameters are as follows: $\mathrm{V}=12 \mathrm{~V}, \mathrm{i}=0.8, \mathrm{R}=15, \mathrm{~L}=12 \mathrm{Mh}, \quad \mathrm{N}_{\mathrm{r}}=48 \quad, \mathrm{~B}=0.005$, step angle $7.5^{\circ}$,operating temperature $\left[-30^{\circ}, 80^{\circ}\right]$.

If the input angle is $\theta_{1}$, and the actual rotation angle of stepping motor is $\theta_{2}$ after received electrical signal, it 
canbe considered that the transfer function of the stepping motor as shown in equation (3). This is a differential equations of $\theta_{2}$ and $\theta_{1}$, after derivation obtained the transfer function of the stepping motor (4).

$$
\begin{gathered}
\mathrm{G}(\mathrm{s})=\frac{\theta_{1}(\mathrm{~s})}{\theta_{2}(\mathrm{~s})} \\
\mathrm{G}(\mathrm{s})=\frac{\theta_{1}(\mathrm{~s})}{\theta_{2}(\mathrm{~s})}=\frac{\frac{1}{2} \mathrm{~N}_{\mathrm{r}}{ }^{2} \mathrm{Li}_{\mathrm{a}}{ }^{2}}{\mathrm{Js}^{2}+\mathrm{Bs}+\frac{1}{2} \mathrm{~N}_{\mathrm{r}}{ }^{2} \mathrm{Li}_{\mathrm{a}}{ }^{2}}
\end{gathered}
$$

Sense of the parameters in the equation as follows: $i_{a}$ :phase current, $R$ : resistance of windings, $L$ :coil inductance of windings, $\mathrm{N}_{\mathrm{r}}$ :rotor teeth,B:viscous friction coefficient,J:rotational inertia of the load. Thereby obtaining the transfer function of the stepping motor (5).

$$
\mathrm{G}(\mathrm{s})=\frac{11.059}{0.96 \mathrm{~s}^{2}+0.005 \mathrm{~s}+11.059}
$$

Control algorithm of the stepping motor and system kinematics model constitute P-AFS control model, wherein the mathematical model is relationship between vehicle speed, road equivalent radius and swiveling angle of headlamps, and control the swiveling angle of headlamps actually is control the stepper motor .

PID algorithm is the most commonly used control algorithm in the industry, and can satisfy most requirements, so use PID algorithm control the swiveling angle of headlamps [7]. Use an improved genetic algorithm optimize PID parameters . respectively adopts ten binary-code strings to represent three variables

$K_{P} 、 K_{I}, K_{D}$, genetic length is 30 , initial population size is $\mathrm{M}=50$,iterations is 300 , selection algorithm is roulette method, crossover rate and mutation rate as formula (6) and(7) .

$$
\begin{aligned}
& \mathrm{p}_{\mathrm{c}}^{\mathrm{t}}=\mathrm{p}_{\mathrm{c}}^{\mathrm{t}-1}-\left[\mathrm{p}_{\mathrm{c}}^{0}-0.25\right] / 300 \\
& \mathrm{p}_{\mathrm{m}}^{\mathrm{t}}=\mathrm{p}_{\mathrm{m}}^{\mathrm{t}-1}-\left[0.25-\mathrm{p}_{\mathrm{m}}^{0}\right] / 300
\end{aligned}
$$

$\mathrm{p}_{\mathrm{c}}^{\mathrm{t}}$ : crossover probability of generation $\mathrm{t}, \mathrm{p}_{\mathrm{m}}^{\mathrm{t}}$ : mutation probability of generation $t$.

Objective function is:

$$
\left\{\begin{array}{r}
\mathrm{J}=\int_{0}^{\infty}\left(\mathrm{w}_{1}|\mathrm{e}(\mathrm{t})|+\mathrm{w}_{2} \mathrm{u}^{2}(\mathrm{t})\right) \mathrm{dt}+\mathrm{t}_{\mathrm{u}} \mathrm{w}_{3} \\
\mathrm{y}(\mathrm{t}) \geq \mathrm{y}(\mathrm{t}-1) \\
\mathrm{J}=\int_{0}^{\infty}\left(\mathrm{w}_{1}|\mathrm{e}(\mathrm{t})|+\mathrm{w}_{2} \mathrm{u}^{2}(\mathrm{t})\right) \mathrm{dt}+\mathrm{t}_{\mathrm{u}} \mathrm{w}_{3} \\
+\mathrm{w}_{4}|\mathrm{y}(\mathrm{t})-\mathrm{y}(\mathrm{t}-1)| \quad \mathrm{y}(\mathrm{t})<y(\mathrm{t}-1)
\end{array}\right.
$$

Where, e (t):system error, $u(t)$ :controller output, $t$ u: rise time, $\mathrm{y}(\mathrm{t})$ : output value of the controlled object, $\mathrm{w}_{1}, \mathrm{w}_{2}, \mathrm{w}_{3}, \mathrm{w}_{4}$ weighting coefficients $\mathrm{w}_{1}=1, \mathrm{w}_{2}=$ $0.01, \mathrm{w}_{3}=3, \mathrm{w}_{4}=200$. The fitness function is expressed as: $\mathrm{F}=1 / \mathrm{J}$, variation range of $\mathrm{K}_{\mathrm{P}}, \mathrm{K}_{\mathrm{I}}, \mathrm{K}_{\mathrm{D}}$ are set to $[0,50],[0,30],[0,10]$,after 300 iterations calculated $\mathrm{K}_{\mathrm{P}}, \mathrm{K}_{\mathrm{I}}, \mathrm{K}_{\mathrm{D}}$ were $46.8750,3.8086,4.6875$.

\section{SIMULATION}

Build simulation platform combined with carsim and simulink to test and verify the entire model. Set in carsim simulation conditions: select B-Class hatchback, vehicle total mass is $1395 \mathrm{~kg}$, the distance from center of mass to front axle is $1.04 \mathrm{~m}$, the distance from center of mass to the rear axle is $1.42 \mathrm{~m}$, all four tires $185 / 65 \mathrm{R} 15$, front and rear all independent suspension,speed control, set a target vehicle speed $36 \mathrm{~km} / \mathrm{h}$, without braking, road driver track model is no offset and $1.5 \mathrm{~s}$ pre-targeting time. And set carsim solver step is $0.01 \mathrm{~s}$, output step is $0.02 \mathrm{~s}$.

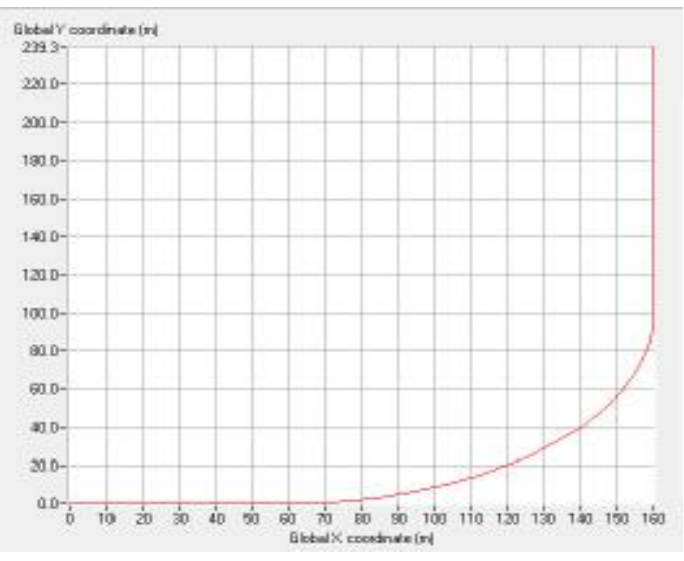

Figure2. simple road model

Firstly set up a simple road, the road as shown in Fig. 2.It should be noted that the simple road model set here is in accordance with national standards [9-10],so it can reflect the actual traveling road, and adopt 80 points to form the road,there is a coordinate point every $4.45 \mathrm{~m}$ average.

Confederative simulation model of carsim and simulink as shown in Fig. 3, set the simulation time is 28 s .

Analyze the simulation results: we can see from Fig.4, when at about $2.2 \mathrm{~s}$, there are approximately $40 \mathrm{~m}$ distance from the vehicle to curve, headlights controlled by P-AFS begin to swivel;when about 6 s, that is when the car into the curve, the swiveling angle reach the maximum; when at about $5.5 \mathrm{~s}$ headlights controlled by AFS begin to swivel, vehicle is about entering curve, the driver already have a steering wheel angle input;when about $7 \mathrm{~s}$, that is when the car already runing in the curve about $10 \mathrm{~m}$, the swiveling angle of headlamps controlled by AFS reach the maximum; when about18s, that is the car is not yet out of the curve, the swiveling angle of headlights controlled by P-AFS has begin to reduce ;to about $22 \mathrm{~s}$, the car is just out of the curve, swiveling angle of headlamps controlled by P-AFS basically reduce to $0^{\circ}$, at this time vehicle just out of the curve; to about $23 \mathrm{~s}$, when the car traveling on the straight road for about $13 \mathrm{~m}$, swiveling angle of headlamps controlled by AFS basically reduce to $0^{\circ}$. 


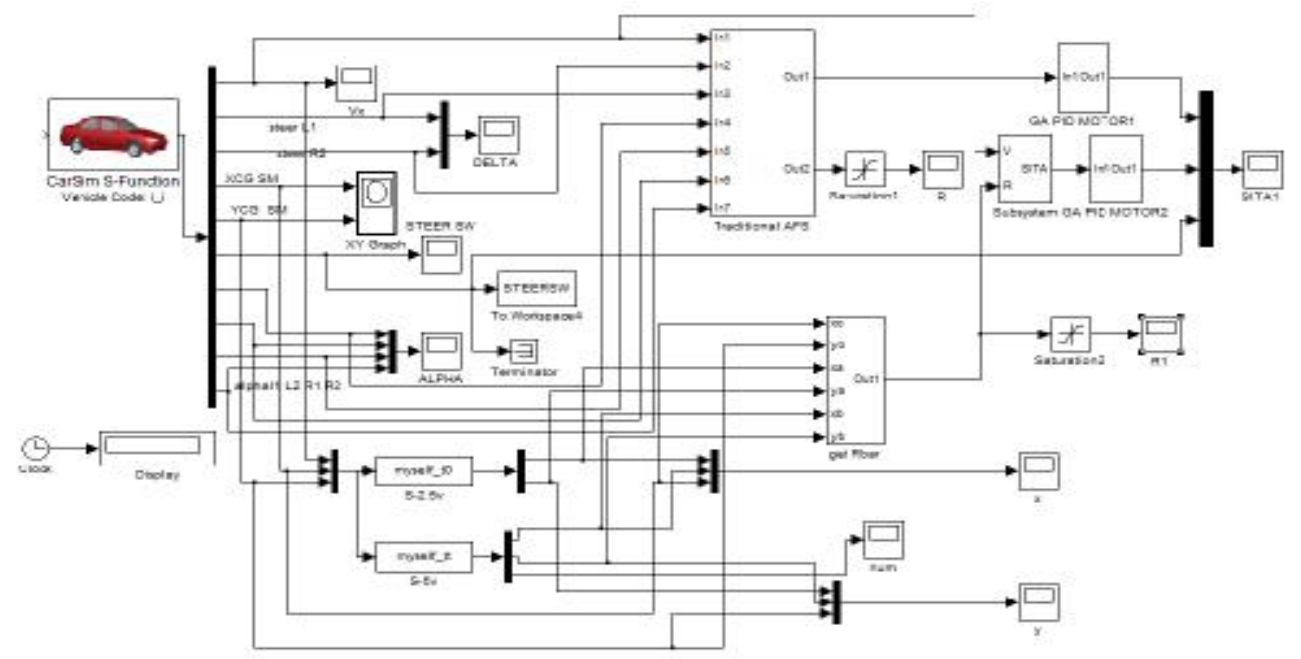

Figure3 Combined simulation model of simulink and carsim

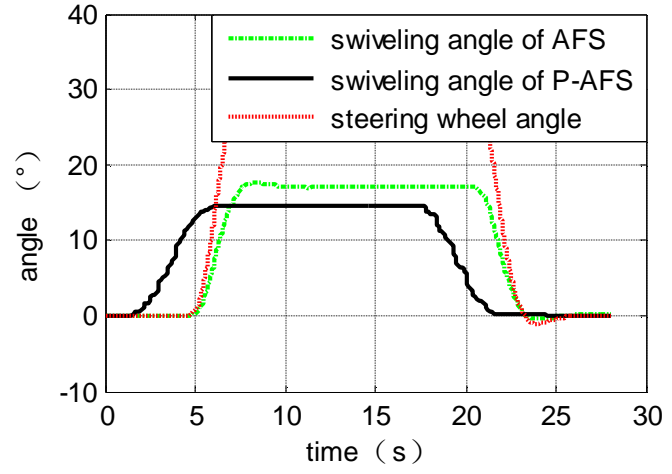

Figure4 simple road model simulation results

The simulation results shows:P-AFS algorithm fully meet the predictive requirements, it can effectively eliminate hysteresis of conventional AFS system. In addition, maximal swiveling angle of headlamps controlled by P-AFS is about $15^{\circ}$, but maximal swiveling angle of headlamps controlled by AFS is about $17.5^{\circ}$.Formula of two models are the same, reasons for the differences is :conventional AFS controls the swiveling angle of headlamps based on vehicle speed and front road wheel steer angle signals, the actual curve radius is $100 \mathrm{~m}$, when the car is

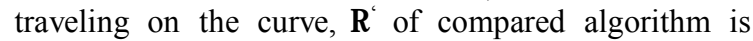
about $85 \mathrm{~m}, \overline{\mathrm{R}}$ of P-AFS is close to $100 \mathrm{~m}$. The reason of great devition of compared algorithm is:tire slip angle impact the actual turning radius of vehicle, when the vehicle is traveling on the curve, the front road wheel steer angle is about $1.7^{\circ}$, while the slip angle of left front wheel is about $-0.2^{\circ}$, it can be shown the correction amount that the tire slip angle for the turning radius is extremely large.

Then set a simulation condition closer to the actual situation, export part of the underlying data from the electronic map data, get some routes data of National Road 217, latitude and longitude coordinates of the start point and end point is $(100.2076784662133,100.2076784662133)$ (100.2082464302012,29.46863996175012) .

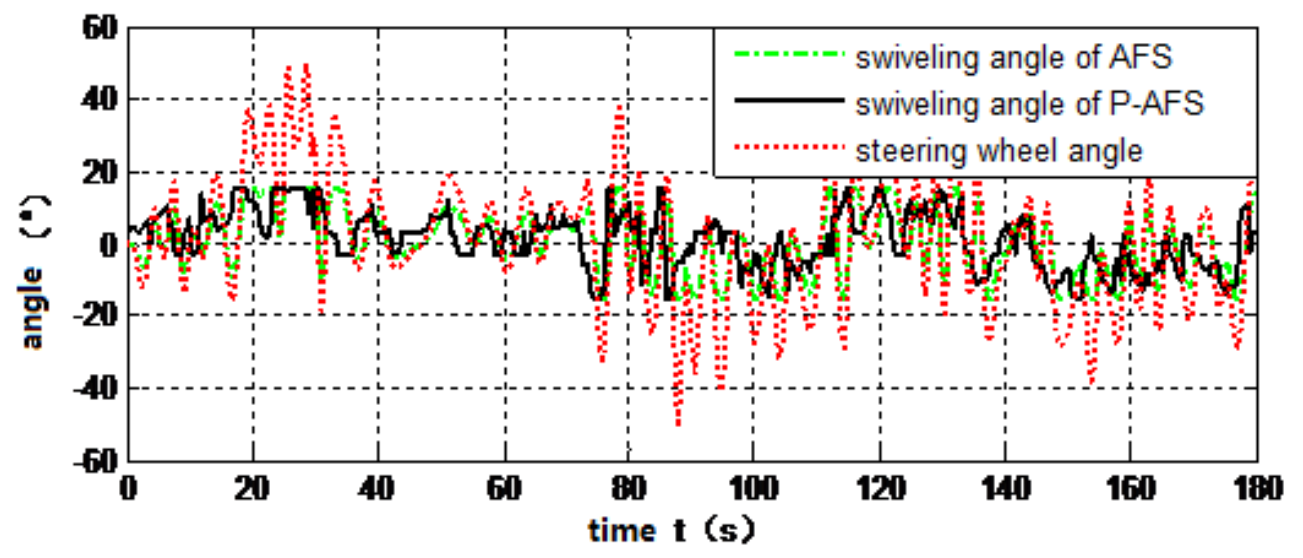

Figure 5 simulation results of actual road 
This route is very representative,consist of circular curve, transition curve, straight line and an S-type curve. Route length about $1.9 \mathrm{~km}$, including 120 coordinates. The latitude and longitude of this road via the coordinate transformation, imported into carsim, set simulation conditions remaining the same, simulation time set to 180 s, obtain simulation results shown in Fig. 5.

Simulation results shows in Fig 5: swiveling angle of headlamps controlled by P-AFS is always ahead swiveling angle of headlamps controlled by AFS, PAFS can effectively improve the driver's field of vision when driving at night.However, result of P-AFS is not smooth and sometimes sharp peaks appeared sometimes is quite different from the results obtained by the conventional AFS algorithm. The reason for this phenomenon is: the points on the curve road is not very dense and the underlying data of electronic map have some differences from the actual road which can not be avoided in the data collection process . In addition, the actual trajectory of vehicle and the road still have some differences.

\section{CONCLUSION}

Proposed an algorithm of P-AFS, which can effectively use navigation signals and electronic map information and control the swiveling angle of headlamps based on vehicle speed and road equivalent radius,given the concept and solving process of equivalent radius.

Established a confederative simulation model of carsim and simulink, tested and verified the algorithm of P-AFS algorithm, the algorithm can effectively solve the hysteresis of traditional AFS, and improve accuracy.
Verify the traditional AFS model is not accurate , which controls the swiveling angle of headlights based on vehicle speed and front wheel rotation angle.

High-precision electronic maps and accurate mapmatching algorithm is premise to ensure the validity and accuracy of the algorithm.

\section{REFERENCES}

[1] Chi Haitao."Research on bending mode algorithm of Adaptive front-lighting system with simulation of driver preview behavior," Changchun: Jilin University ,2012.

[2] Michael Hamm. “Adaptive Lighting Functions History and FuturePerformance Investigations and Field Test for User's Acceptance," 2002,SAE Paper No.2002-01-0526.

[3] Cao Qingqing Ding Zhizhong."Vehicle AFS modeling and simulation based on two degrees of freedom. Journal of electronic measurement and instrumentaion," 2014,vol.28 No.4 pp. 447-453.

[4] Meng Deliang,Han Junfeng.. "Study on model of vehicle light steering angles of AFS system", Automotive Technology, 2011,No.5 pp.20-23.

[5] Yang Sensen "Navigation of Driverless vehicle based on GPS/INS/LIDAR” .Shanghai. Shanghai Jiao Tong University . 2013.

[6] Dario D.Salvucci,Andrew Liu, "The time course of lane change: Driver control and eye-movement behavior".Transportation Research part F5, 2002,pp. 123-133.

[7] Liu Jinkun. "Advanced PID control and MATLAB simulation". Electronic Industry Press, 2003,pp. 5-17.

[8] LEI Yingjie, Shanwen."MATLAB genetic algorithm toolbox and application". Xi'an University of Electronic Science and Technology Press, 2014.pp.67-102.

[9] The People's Republic of China Ministry of Transportation .JTGB01-2003."Technical standard of highway engineering”. People's Communications Press .2004.

[10] The People's Republic of China Ministry of Transportation.JTGD20-2006. "Design specification for highway alignment". Beijing Normal University Press .2006. 